\title{
Complement component C5a Promotes Expression of IL-22 and IL-17 from Human T cells and its Implication in Age-related Macular Degeneration
}

Baoying Liu', Lai Wei ${ }^{1}$, Catherine Meyerle², Jingsheng Tuo ${ }^{1}$, H Nida Sen ${ }^{1}$, Zhiyu Li', Sagarika Chakrabarty ${ }^{1}$, Elvira Agron ${ }^{2}$, Chi-Chao Chan ${ }^{1}$, Michael L Klein ${ }^{3}$, Emily Chew ${ }^{2}$, Frederick Ferris ${ }^{2}$ and Robert B Nussenblatt ${ }^{*}$

\begin{abstract}
Background: Age related macular degeneration (AMD) is the leading cause of irreversible blindness in elderly populations worldwide. Inflammation, among many factors, has been suggested to play an important role in AMD pathogenesis. Recent studies have demonstrated a strong genetic association between AMD and complement factor $\mathrm{H}(\mathrm{CFH})$, the down-regulatory factor of complement activation. Elevated levels of complement activating molecules including complement component $5 \mathrm{a}$ ( $\mathrm{C} 5 \mathrm{a}$ ) have been found in the serum of AMD patients. Our aim is to study whether $\mathrm{C} 5 \mathrm{a}$ can impact human $\mathrm{T}$ cells and its implication in AMD.

Methods: Human peripheral blood mononuclear cells (PBMCs) were isolated from the blood of exudative form of AMD patients using a Ficoll gradient centrifugation protocol. Intracellular staining and enzyme-linked immunosorbent assays were used to measure protein expression. Apoptotic cells were detected by staining of cells with the annexin-V and TUNEL technology and analyzed by a FACS Caliber flow cytometer. SNP genotyping was analyzed by TaqMan genotyping assay using the Real-time PCR system 7500.

Results: We show that C5a promotes interleukin (IL)-22 and IL-17 expression by human CD4+ $T$ cells. This effect is dependent on B7, IL-1 $\beta$ and IL-6 expression from monocytes. We have also found that C5a could protect human CD4 cells from undergoing apoptosis. Importantly, consistent with a role of C5a in promoting IL-22 and IL-17 expression, significant elevation in IL-22 and IL-17 levels was found in AMD patients as compared to non-AMD controls.

Conclusions: Our results support the notion that C5a may be one of the factors contributing to the elevated serum IL-22 and IL-17 levels in AMD patients. The possible involvement of IL-22 and IL-17 in the inflammation that contributes to AMD may herald a new approach to treat AMD.
\end{abstract}

\section{Background}

Age related macular degeneration (AMD) is clinically characterized by degenerative changes in the macula, the region of the retina that permits fine central vision. One of the key pathological features of AMD is the development of large drusen, extracellular deposits located between Bruch's membrane and the retinal pigment epithelium (RPE). These large drusen and the associated

\footnotetext{
* Correspondence: drbob@nei.nih.gov

'Laboratory of Immunology, National Eye Institute, National Institutes of Health, Bethesda, MD 20892, USA

Full list of author information is available at the end of the article
}

RPE changes are the major risk factors for the development of advanced AMD, which can be classified into two subtypes: dry (geographic atrophic) and wet (neovascular) [1]. Inflammation has been suggested to play an important role in AMD pathogenesis [2,3].

Genetic studies have demonstrated strong associations between AMD and several gene variants in genes coding for complement proteins, including complement factor $\mathrm{H}$ (CFH), factor $\mathrm{B} / \mathrm{C} 2$, and $\mathrm{C} 3$ [4-12]. $\mathrm{CFH}$ is a factor that down-regulates complement activation. It is commonly thought that $\mathrm{CFH}$ polymorphism leads to dysregulation of alternative complement activation which may contributes

\section{() Biomed Central}


to AMD pathogenesis [13]. However, the mechanism by which CFH regulates AMD progress is still not clear. Systemic activation of the complement cascade has been implicated in AMD patients [14-16]. C5a, among many alternative complement activation molecules, are elevated in peripheral blood of AMD patients [15,16]. Locally, C5a and $\mathrm{C} 3 \mathrm{a}$ accumulate in drusen and are shown to promote choroidal neovascularization (CNV) [17], which is the hallmark of wet AMD.

Recently, a subset of effector helper T cells, IL-17-producing $\mathrm{T}$ cell (Th17), is implicated in the pathogenesis of various autoimmune diseases including uveitis, arthritis, multiple sclerosis, psoriasis and inflammatory bowel disease [18-20]. Proinflammatory cytokines, including IL-1 $\beta$, IL-6, IL-23, IL-21 and TNF $\alpha$, as well as transcription factor RORC, are responsible for differentiation and maintenance of Th17 cells within human body [21-24]. Recent evidence from the mouse suggests that $\mathrm{C} 5$ a provides both costimulatory and survival signals to $\mathrm{CD} 4^{+} \mathrm{T}$ cells and induces Th17 cytokine expression [25,26]. However, it is still not clear if C5a can impact human T cells and if Th17 cells are associated with AMD.

Here we showed that $\mathrm{C} 5$ a protected human $\mathrm{CD} 4^{+} \mathrm{T}$ cells from undergoing apoptosis and C5a promoted IL-22 and IL-17 expression from CD4 $4^{+} \mathrm{T}$ cells of AMD patients and normal subjects as well. Intriguingly, consistent with previous observation of elevated C5a expression in the serum of AMD patients $[15,16]$, we found significantly increased levels of IL-22 and IL-17 in the sera of AMD patients, suggesting possible roles of IL-22 and IL-17 in the inflammation that contributes to AMD.

\section{Methods \\ Patients}

PBMCs were obtained from the peripheral blood of AMD patients and healthy subjects in compliance with institutional review board (IRB) protocols after informed consent at the National Institutes of Health (NIH). The written consents were obtained. Our study has obtained ethics approval from the neuroscience IRB of NIH. AMD subjects were diagnosed with wet AMD without accompanied systemic autoimmune diseases or other immunerelated diseases, as well as polypoidal vasculopathy by experienced clinicians. We excluded patients with a history of cancer within the past 5 years or patients with active inflammatory diseases. Clinical characteristics, demographic data, and single-nucleotide polymorphism information of complement associated molecules are provided in Table 1 and 2.

\section{Cell sorting}

To sort $\mathrm{CD}^{+}{ }^{+} \mathrm{T}$ cells and monocytes, $1 \times 10^{7}$ PBMCs were stained with allophycocyanin-labeled CD3 (clone
UCHT1, BD Biosciences), PE-labeled CD4 (clone RPA-T4, BD Biosciences), or FITC labeled CD14 (clone M5E2, BD Biosciences) for 20 minutes in 1\% BSA PBS staining buffer. Cells were then washed and subsequently sorted on a FACS Aria (BD Biosciences). BD FACSDiva software was used to sort the cells.

\section{Cell culture and flow cytometry}

PBMC cells were cultured in RPMI 1640 medium (Invitrogen, Carlsbad, CA) containing 10\% fetal bovine serum (Gemini Bioproducts, West Sacramento, CA) supplemented with $2 \mathrm{mM}$ glutamine and $1 \times$ antibiotics. For $\mathrm{T}$ cell and monocytes separation, PBMCs were cultured in the same RPMI medium described above and then stained with anti-CD3 and anti-CD4 antibodies for T cell and anti-CD14 for monocyte separation. Cells were treated with or without C5a (50 ng/ml from R\&D Systems, endotoxin level $<1.1 \mathrm{EU}$ per $1 \mu \mathrm{g}$ of protein) and a C5aR antagonist $(2.5 \mathrm{ug} / \mathrm{ml}$ from Jerini Ophthalmic Inc, also called JPE-1375, is a hexameric linear peptidomimetic molecule that inhibits $\mathrm{C} 5 \mathrm{a}$ binding to the human $\mathrm{C} 5 \mathrm{aR}$ ). Anti-B7.1 and B7.2 antibodies $(10 \mu \mathrm{g} / \mathrm{ml}$ of each) or antiIL-1 $\beta(10 \mu \mathrm{g} / \mathrm{ml})$ and anti-IL-6 $(10 \mu \mathrm{g} / \mathrm{ml})$ neutralization antibodies were added into the cell culture in indicated experiments. Intracellular staining was performed after 5 days of C5a culture. Cells were stimulated with PMA (10 $\mathrm{ng} / \mathrm{ml})$, ionomycin $(0.5 \mu \mathrm{g} / \mathrm{ml})$ and Golgistop for 4 hours at $37^{\circ} \mathrm{C}$ before intracellular staining. $5 \times 10^{5}$ cells were stained with FITC labeled CD45RA (clone HI100, BD Biosciences), PE-IL-22 (clone 22URTI, eBioscience), or PE-IL-17A (clone eBio64DEC17, eBioscience), perCP-CD4 (clone SK3, BD Biosciences) and allophycocyanin-labeled CD3. The intracellular staining procedure was based on the BD Bioscience protocol. Briefly, cells were firstly stained with cell surface markers (anti-CD4, antiCD45RA), and then permeabilized and proceeded to intracellular staining (anti-LI-17A or IL-22). Cells were acquired by a FACSCalibur flow cytometer (BD Biosciences) and analyzed by FlowJo software (TreeStar, San Jose, CA).

\section{Cytokine Analysis}

Sera from patients or supernatants collected from cell culture were tested by ELISA for IL-22 and IL-17, or sent for multiplex cytokine analysis (Aushon Biosystems). IL-22 and IL-17A ELISA kits were purchased from R\&D Systems, Inc. (Minneapolis, MN) and were performed based on kit protocols.

\section{Apoptosis Assay}

Apoptotic cells were detected by staining cells with both the annexin-V-FITC (BD Biosciences) and TUNEL technology (Roche, Indianapolis, IN) according to the 
Table 1 Clinical information of AMD patients

\begin{tabular}{|c|c|c|c|c|c|c|c|c|}
\hline $\begin{array}{l}\text { PT } \\
\text { number }\end{array}$ & $\begin{array}{l}\text { Race, Age, } \\
\text { Gender }\end{array}$ & $\begin{array}{l}\text { Type of } \\
\text { Disease }\end{array}$ & $\begin{array}{l}\text { CFH } \\
\text { rs1061170 }\end{array}$ & $\begin{array}{l}\text { C2/CFB } \\
\text { Rs933739 }\end{array}$ & $\begin{array}{l}\text { C3 } \\
\text { Rs2230199 }\end{array}$ & Ocular therapy+ & $\begin{array}{l}\text { Co- } \\
\text { Morbidities* }\end{array}$ & Medications++ \\
\hline 1 & W, 94, F & Wet OU & TC & GG & $\mathrm{CC}$ & anti-VEGF, PDT & 19 & $\mathrm{H}$ \\
\hline 2 & $W, 80, F$ & Wet OU & $\pi$ & GG & $\mathrm{CC}$ & anti-VEGF, PDT & 8 & $W, L, X$ \\
\hline 3 & W, 97, F & Wet OU & TC & GG & $\mathrm{CC}$ & anti-VEGF, Isteroids & none & W \\
\hline 4 & $W, 92, F$ & Wet OU & TC & GG & $\mathrm{CC}$ & anti-VEGF & $14,16,21$ & $Z, G, O, B B$ \\
\hline 5 & W, 91, M & Wet OU & TC & GG & $\mathrm{CC}$ & anti-VEGF & $2,7,18,14$ & $W, H, T, G, D, C, B$ \\
\hline 6 & W, 91, M & Wet OU & TC & GG & CG & anti-VEGF & $10,11,14,15$ & $G, C, H, B, E$ \\
\hline 7 & W, 83, F & Wet OU & $\mathrm{CC}$ & GG & $C G$ & anti-VEGF, PDT & $8,14,16$ & $W, Z, G$ \\
\hline 8 & $W, 79, F$ & $\begin{array}{l}\text { Wet OD, Dry } \\
\text { OS }\end{array}$ & $\mathrm{CC}$ & GG & CG & anti-VEGF, Laser Rx & $14,15,21$ & W, C, G, M, BB \\
\hline 9 & W, 74, M & Wet OU & $\mathrm{CC}$ & GG & GG & anti-VEGF, Laser Rx & $7,11,14,15$ & $W, B B, E, Y, D, H, L, C, S$ \\
\hline 10 & W, 77, M & $\begin{array}{l}\text { Wet OD, Dry } \\
\text { OS }\end{array}$ & $\mathrm{TC}$ & GG & $C G$ & anti-VEGF, Isteroids & 14,15 & $W, L, C, H, R$ \\
\hline 11 & W, 74, M & $\begin{array}{l}\text { Dry OD, Wet } \\
\text { OS }\end{array}$ & $\pi$ & GG & CC & anti-VEGF & $3,15,16$ & $W, Z, A$ \\
\hline 12 & $W, 82, F$ & Wet OU & $\pi$ & GG & GG & anti-VEGF, PDT & 10,11 & $W, E, B B, L, F$ \\
\hline 13 & $W, 81, F$ & Wet OU & CC & GG & CG & anti-VEGF, laser Rx & $7,14,15$ & $C, G, V$ \\
\hline 14 & W, 75, M & $\begin{array}{l}\text { Wet OD, Dry } \\
\text { OS }\end{array}$ & TC & GG & $\mathrm{CC}$ & None & $14,15,23$ & $C, G, H$ \\
\hline 15 & W, 67, M & $\begin{array}{l}\text { Wet OD, Dry } \\
\text { OS }\end{array}$ & TC & GG & $\mathrm{CC}$ & anti-VEGF, PDT & $8,15,20$ & $W, L, X, C, H, F$ \\
\hline 16 & W, 72, F & Wet OU & TC & GG & $\mathrm{CC}$ & anti-VEGF, Isteroids & 12,16 & Z, I, G, W \\
\hline 17 & W, 74, M & Wet OU & $\mathrm{CC}$ & $C G$ & GG & $\begin{array}{l}\text { anti-VEGF, laser } \mathrm{Rx} \text {, } \\
\text { PDT }\end{array}$ & 20 & $F, V$ \\
\hline 18 & W, 77, F & Wet OU & CC & - & $\mathrm{CC}$ & $\begin{array}{l}\text { anti-VEGF, PDT, } \\
\text { Isteroid }\end{array}$ & 8 & $x$ \\
\hline 19 & W, 75, M & $\begin{array}{l}\text { Dry OD, Wet } \\
\text { OS }\end{array}$ & CC & GG & $\mathrm{CC}$ & anti-VEGF & 11,15 & $W, E, C, L$ \\
\hline 20 & W, 82, M & Wet OU & - & - & - & none & $\begin{array}{l}3,5,6,7,11 \\
19\end{array}$ & $P, B, G, A, E, D$ \\
\hline 21 & W, 72, M & Wet OU & $\mathrm{CC}$ & GG & CG & anti-VEGF, Isteroid & 7,14 & $\mathrm{H}, \mathrm{G}, \mathrm{D}$ \\
\hline 22 & W, 83, M & $\begin{array}{l}\text { Wet OD, Dry } \\
\text { OS }\end{array}$ & $\mathrm{TC}$ & GG & $\mathrm{CC}$ & anti-VEGF, Isteroid & 14,15 & $W, L, H, G, C$ \\
\hline 23 & W, 83, M & $\begin{array}{l}\text { Wet OD, Dry } \\
\text { OS }\end{array}$ & $\pi$ & GG & GG & anti-VEGF, PDT & $14,15,22$ & $\mathrm{~B}, \mathrm{~W}, \mathrm{G}, \mathrm{C}$ \\
\hline 24 & $W, 88, F$ & $\begin{array}{l}\text { Dry OD, Wet } \\
\text { OS }\end{array}$ & TC & GG & $\mathrm{CC}$ & anti-VEGF & 19 & W, H, \\
\hline 25 & W, 70, M & $\begin{array}{l}\text { Wet OD, Dry } \\
\text { OS }\end{array}$ & $\mathrm{TC}$ & GG & CC & anti-VEGF & 10 & W \\
\hline 26 & $W, 83, F$ & $\begin{array}{l}\text { Wet OD, Dry } \\
\text { OS }\end{array}$ & $\pi$ & GG & $\mathrm{CC}$ & anti-VEGF, Isteroids & $8,13,14,17$ & $Q, G, Z, W$ \\
\hline 27 & W, 80, M & $\begin{array}{l}\text { Dry OD, Wet } \\
\text { OS }\end{array}$ & CC & GG & $C G$ & anti-VEGF & $\begin{array}{l}7,8,14,15,21 \\
25\end{array}$ & $\begin{array}{l}\text { W, L, BB, Q, G, C, M, AA, } \\
D, B B\end{array}$ \\
\hline 28 & W, 95, M & $\begin{array}{l}\text { Dry OD, Wet } \\
\text { OS }\end{array}$ & $\pi$ & CG & $\mathrm{CC}$ & anti-VEGF & $1,14,15,22$ & $W, E, B, K, B B, C, G, T$ \\
\hline 29 & $W, 79, F$ & Wet OU & CC & GG & CG & anti-VEGF, PDT & $7,21,24$ & $W, L, D, V, C C, N$ \\
\hline 30 & W, 84, M & Wet OU & TC & GG & $\mathrm{CC}$ & PDT, Laser Rx & 5,8 & $\mathrm{G}, \mathrm{H}, \mathrm{C}, \mathrm{X}, \mathrm{A}$ \\
\hline 31 & W, 80, M & $\begin{array}{l}\text { Wet OD, Dry } \\
\text { OS }\end{array}$ & $\mathrm{CC}$ & $C G$ & $C G$ & anti-VEGF & $4,8,15$ & $W, B B, L, B, E, N, D, X$ \\
\hline 32 & $W, 97, F$ & Wet OU & - & - & - & None & 2 & $J, B$ \\
\hline 33 & W, 77, M & Wet OU & TC & GG & $\mathrm{CC}$ & anti-VEGF, Laser Rx & 11 & $W, L, E$ \\
\hline 34 & W, 57, M & $\begin{array}{l}\text { Wet OU, Wet } \\
\text { OS }\end{array}$ & $\pi$ & GG & $C G$ & anti-VEGF & $3,7,14,15,26$ & $A, C, D, G, B B, D D$ \\
\hline 35 & $W, 67, F$ & Wet OU & CT & GG & $C G$ & anti-VEGF & $14,15,16,21$ & $\mathrm{G}, \mathrm{M}, \mathrm{Z}, \mathrm{BB}, \mathrm{EE}$ \\
\hline 36 & $W, 82, F$ & Wet OU & CT & $C G$ & CG & anti-VEGF & $7,8,14,15,16$ & $C, G, K, Q, Z, B B$ \\
\hline 37 & $W, 84, F$ & Wet OS & CC & GG & $\mathrm{CC}$ & anti-VEGF & 15,16 & $C C, L, G, Z$ \\
\hline
\end{tabular}


Table 1 Clinical information of AMD patients (Continued)

\begin{tabular}{llllllll}
\hline 38 & W, 83, F & Wet OU & CT & GG & CG & anti-VEGF & 9, 14, 15, 28 \\
39 & W, 84, F & Wet OS & TT & GG & CC & anti-VEGF & 16, 27 \\
40 & W, 90, F & Wet OU & CC & GG & CC & anti-VEGF & 27 \\
\hline
\end{tabular}

Ocular therapy+

anti-VEGF- either Lucentis or Avastin intravitreal injections; Isteroids-Intravitreal steroid injections; PDT- Photodynamic

therapy; Laser Rx- focal laser ablation of choroidal neovascularization

Co-morbidities*

1. anemia; 2. atrial fibrillation; 3. benign prostatic hypertrophy; 4. cerebrovascular accident; 5. COPD; 6. coronary artery disease; 7. depression; 8. diabetes; 9. Colon Cancer; 10. Glaucoma; 11. GERD; 12. gout; 13. Hashimoto's thyroiditis; 14 . hypertension; 15. hypercholesterolemia; 16. hypothyroid; 17 . h/o low grade vitritis; 18. Lyme Disease; 19. myocardial infarction; 20. Ocular Hypertension; 21. osteoporosis; 22. pacemaker; 23. prostate cancer; 24. seasonal allergies 25. testicular failure; 26. Asthma; 27. Uterine cancer post hysterectomy and radiation 28: Breast cancer.

Medications++

A. Anti-Benign Prostatic Hypertrophy; B. Anti-Coagulants; C. Anti-Cholesterol; D. Anti-Depressants; E. Anti-GERD; F. Anti-Glaucoma drops; G. Anti-Hypertensive medication; H. Aspirin; I. Colchicine; J. Digoxin; K. Ferrous Fumarate; L. Fish Oil; M. Fosamax; N. Gapapentin; O. Glucosamine; P. Inhalers; Q. Insulin; R. Loratadine; S. Magnesium Citrate; T. Meclizine; U. Megestrol acetate; V. NSAIDs; W. Ocuvites; X. Oral Hypoglycemic agents; Y. Scopolamine; Z. Synthroid; AA. Testosterone injections; BB. Vitamins; CC. Premarin; DD. Singulair; EE. Calcitonin.

manufacturer's instructions. Phospho-Bad expression was detected by western blot using anti-Phospho-Bad antibody (Cell Signaling Technology).

\section{SDS-PAGE and Western blotting}

A total of 5 million $\mathrm{T}$ cells were lysed in $100 \mu \mathrm{l}$ lysis buffer [50 mM Tris-Cl, 1\% Triton X-100, $100 \mathrm{mM}$ $\mathrm{NaCl}, 2 \mathrm{mM}$ EDTA, $50 \mathrm{mM} \mathrm{NaF}, 50 \mathrm{mM}$ glycerol-phosphate, $1 \mathrm{mM} \mathrm{NaVO}_{4}$ and $1 \times$ protease inhibitor cocktail (Roche)]. Complete cell lysis was achieved by immediately vortexing the cells and then boiling in an equal amount of $2 \times$ SDS protein loading buffer at $95^{\circ} \mathrm{C}$ for 5 minutes. Cell debris was removed by centrifugation at 12, $000 \mathrm{rpm}$ for $3 \mathrm{~min}$. Twenty microliter of each sample was loaded into a $12 \%$ SDS-polyacrylamide gel containing a $4 \%$ stacking gel. Immunoblotting was carried out. Primary antibodies of anti-Phospho-Bad, anti-Bad were purchased from Cell Signaling Technology (Beverly, MA). Anti- $\beta$-actin antibody was from Santa Cruz Biotechnology, Inc.(Santa Cruz, CA).

\section{SNP Genotyping}

Genomic DNA was extracted from the peripheral blood of each individual using Promega Wizard Genomic DNA Purification kit. The samples were analyzed by TaqMan genotyping assay using the Real-time PCR system 7500 (Applied Biosystems, Foster City, CA, USA). The primers and probes for $C 2 / C F B$ rs9332739 and C3 rs2230199 were from the inventory SNP assay while CFH rs1061170 were custom-designed from Applied Biosystems. Genotypes were determined based on the fluorescence intensities of FAM and VIC. The call rates of 3 assays were $>98.5 \%$ and the call accuracies (consistency of duplicate wells of selected samples) were $100 \%$.

\section{Statistical Analysis}

Non-parametric methods (Wilcoxon two-sample test) were used since the expression of IL17 and IL22 does not follow a parametric distribution. To evaluate if the expression of these 2 cytokines follows a normal distribution, we visually checked the histograms as well as used the Kolmogorov-Smirnov method. For the association study between IL-22/IL-17 and some characteristics of patients $(\mathrm{CFH}, \mathrm{C} 2 / \mathrm{CFB}, \mathrm{C} 3$ genotypes, gender, comorbidities of diabetes, hypertension and hypercholesterolemia), Wilcoxon's nonparametric two-sample rank sum test was used. Age was analyzed using Pearson correlation. The software used for all the analyses was "The SAS System", version 9.2.

\section{Results}

We listed the demographic, clinical information for both controls and AMD patients in Table 1 and Table 2. Ocular therapies, co-morbidities and complement related genetic variance were also included to AMD patients for later data analysis. These information will be used to evaluate confounding factors. All the subjects in this study are Caucasians. There are 45 controls and the age range was from 59 to 87 . Fifty-three percent (53\%) are females and $47 \%$ are males. There are $40 \mathrm{AMD}$ patients in this study and the age range was from 57 to 97 . Fifty percent $(50 \%)$ are females and $50 \%$ are males.

\section{C5a promotes the expression of IL-22 and IL-17 from human $\mathrm{T}$ cells in vitro}

To study the role of $\mathrm{C} 5 \mathrm{a}$ on human $\mathrm{CD} 4^{+} \mathrm{T}$ cells, we used ELISA and intracellular staining to detect cytokine expression. PBMCs from AMD patients and controls were treated with or without $\mathrm{C} 5 \mathrm{a}$ and a $\mathrm{C} 5 \mathrm{aR}$ antagonist for 3 days. Cell supernatants from 14 controls and 14 AMD patients were used for ELISA analysis and are presented side by side in Figure 1A. The addition of C5a greatly increased the expression of IL-22 and IL-17A in PBMC cells from both AMD patients and controls. Blocking C5aR reversed this effect (Figure 1A). Interestingly, we cannot detect the changes of IFN $\kappa$ and IL-4 
Table 2 Healthy Donor Information

\begin{tabular}{|c|c|c|c|c|}
\hline $\begin{array}{l}\text { Donor } \\
\text { number }\end{array}$ & $\begin{array}{l}\text { Race, Age, } \\
\text { Gender }\end{array}$ & $\begin{array}{l}\text { CFH } \\
\text { rs1061170 }\end{array}$ & $\begin{array}{l}\text { C2/CFB } \\
\text { Rs9332739 }\end{array}$ & $\begin{array}{l}\text { C3 } \\
\text { Rs2230199 }\end{array}$ \\
\hline 1 & $W, 61, F$ & $\mathrm{CT}$ & $C G$ & CC \\
\hline 2 & W, 72, M & $\mathrm{CT}$ & GG & $\mathrm{CC}$ \\
\hline 3 & W, 69, M & - & GG & GG \\
\hline 4 & $W, 71, F$ & $\mathrm{CT}$ & GG & $C G$ \\
\hline 5 & W, 75, M & $\pi$ & GG & CC \\
\hline 6 & $W, 65, F$ & $\pi$ & GG & $\mathrm{CC}$ \\
\hline 7 & $W, 66, F$ & $\pi$ & GG & CC \\
\hline 8 & W, 66, M & $\mathrm{CT}$ & GG & $\mathrm{CC}$ \\
\hline 9 & W, 73, M & $\pi$ & GG & CC \\
\hline 10 & W, 61, M & $\mathrm{CC}$ & GG & CC \\
\hline 11 & W, 69, M & $\pi$ & GG & $C G$ \\
\hline 12 & W, 73, F & $\mathrm{CT}$ & GG & $\mathrm{CC}$ \\
\hline 13 & $W, 65, F$ & $\mathrm{CT}$ & GG & $\mathrm{CC}$ \\
\hline 14 & W, 75, F & $\mathrm{CT}$ & GG & $\mathrm{CC}$ \\
\hline 15 & W, 69, M & $\mathrm{CT}$ & GG & $\mathrm{CC}$ \\
\hline 16 & $W, 65, F$ & CC & GG & GG \\
\hline 17 & $W, 65, F$ & $\mathrm{CT}$ & GG & $\mathrm{CC}$ \\
\hline 18 & $W, 65, F$ & - & CG & $C G$ \\
\hline 19 & $W, 62, F$ & $\pi$ & $C G$ & $\mathrm{CC}$ \\
\hline 20 & W, 71, M & $\pi$ & GG & $C G$ \\
\hline 21 & W, 72, M & $\mathrm{CT}$ & GG & $\mathrm{CC}$ \\
\hline 22 & $\mathrm{~W}, 62, \mathrm{M}$ & $\pi$ & GG & CC \\
\hline 23 & $W, 71, F$ & CC & GG & $C G$ \\
\hline 24 & $W, 66, F$ & $\Pi$ & GG & $C G$ \\
\hline 25 & $W, 65, F$ & $\mathrm{CT}$ & GG & $\mathrm{CC}$ \\
\hline 26 & $W, 61, F$ & $\mathrm{CT}$ & GG & CC \\
\hline 27 & $W, 63, F$ & $\mathrm{CT}$ & $C G$ & $\mathrm{CC}$ \\
\hline 28 & $W, 64, F$ & $\mathrm{CT}$ & GG & CC \\
\hline 29 & W, 68, M & $\mathrm{CT}$ & $C G$ & $C G$ \\
\hline 30 & W, 70, M & $\mathrm{CT}$ & GG & - \\
\hline 31 & $W, 87, F$ & - & - & - \\
\hline 32 & W, 59, M & $\mathrm{CC}$ & $\mathrm{CC}$ & CC \\
\hline 33 & $W, 64, F$ & - & - & CC \\
\hline 34 & W, 61, M & $\pi$ & GG & $C G$ \\
\hline 35 & W, 66, M & CC & $C G$ & $C G$ \\
\hline 36 & W, 65, M & $\mathrm{CC}$ & GG & $C G$ \\
\hline 37 & $W, 65, F$ & $\mathrm{CT}$ & GG & GG \\
\hline 38 & $W, 60, F$ & $\mathrm{CT}$ & GG & $C G$ \\
\hline 39 & $W, 63, F$ & $\pi$ & GG & $C G$ \\
\hline 40 & W, 66, F & $\mathrm{CT}$ & $\mathrm{CC}$ & $\mathrm{CC}$ \\
\hline 41 & $W, 77, F$ & - & - & - \\
\hline 42 & W, 65, M & $\mathrm{CT}$ & GG & CC \\
\hline 43 & W, 66, M & $\mathrm{CT}$ & GG & $C G$ \\
\hline 44 & $\mathrm{~W}, 62, \mathrm{M}$ & $\mathrm{CT}$ & GG & CC \\
\hline 45 & W, 66, M & - & - & - \\
\hline
\end{tabular}

levels before and after C5a treatment. We then subgrouped the C5a induced IL-22/IL-17 expression in both controls and AMD patients based on their CFH SNP information (rs1061170). As shown in Figure 1B, there was no significant difference on cytokine expression between controls and AMD patients. However, C5a high response individuals all have the risk $\mathrm{CFH}$ allele genotype (heterozygous/homozygous, TC/CC) in both control and patient groups. Intracellular staining data further confirmed that C5a induced IL-22 and IL-17A secretion from cultured $\mathrm{CD}^{+} \mathrm{CD} 4^{+} \mathrm{T}$ cells after PBMCs were treated for 5 days (Figure 1C).

\section{Monocytes are important for C5a induced IL-22 and IL-17 expression from $\mathrm{T}$ cells}

To address if peripheral monocytes play a role in C5a induced IL-22 and IL-17 expression of $\mathrm{CD}^{+}{ }^{+} \mathrm{T}$ cells, $\mathrm{CD} 14^{+}$monocytes and $\mathrm{CD} 3^{+} \mathrm{CD} 4^{+} \mathrm{T}$ cells were cultured separately or together, with or without C5a $(50 \mathrm{ng} / \mathrm{ml})$ for 72 hours. Protein levels of IL-22 and IL-17A in the culture supernatants were detected by ELISA. As shown in Figure 2A, IL-22 and IL-17 were barely detected in cultures with monocytes or $\mathrm{CD} 4^{+} \mathrm{T}$ cells alone. Interestingly, C5a induced expression of both cytokines only in co-cultures of $\mathrm{CD} 4^{+} \mathrm{T}$ cells and monocytes, suggesting that monocytes are necessary for C5a to promote IL-22 and IL-17 expression. Further experiments showed that only memory $\mathrm{CD} 4^{+} \mathrm{T}$ cells, when co-cultured with monocytes, could produce Th17 cytokines (Figure 2B).

The effects of monocytes on $\mathrm{T}$ cells could be due to either direct interaction between B7.1/B7.2 on monocytes and CD28 on T cells, or indirect effects such as the production of cytokines. C5a treatment promoted both B7.1 and B7.2 expression on monocytes (Figure $2 \mathrm{C}$ ). When a blocking antibody that interrupts the B7-CD28 interaction was added to the culture, the induction of both IL22 and IL- 17 by C5a was diminished, to a similar extent as the effect seen with the C5aR antagonist (Figure 2D). Previous studies have shown that IL- $1 \beta$ and IL- 6 are drivers of Th17 cell polarization $[22,27,28]$. We found a significantly increased expression of both IL- $1 \beta$ and IL- 6 in the supernatants of co-cultures containing both monocytes and T cells and an increased trend for TNF- $\alpha$ although $\mathrm{P}$ value not significant (Figure 2E), but not IFN$\kappa$ or IL-23. Both IL-1 $\beta$ and IL- 6 were produced by monocytes (Figure 2F). We therefore neutralized IL-1 $\beta$ and IL-6 with neutralizing antibodies and found that the induction of IL-22 and IL-17 by C5a were significantly dampened (Figure 2G). Collectively, our results indicate that not only direct interaction between monocytes and $\mathrm{T}$ cells, but also the secretion of IL- $1 \beta$ and IL- 6 by monocytes is required for promotion of Th17 cytokines by C5a.

\section{C5a protects $\mathrm{T}$ cells from undergoing apoptosis}

To fully understand the overall effect of $\mathrm{C} 5 \mathrm{a}$ on $\mathrm{CD} 4^{+} \mathrm{T}$ cells, we examined C5a's effect on $\mathrm{CD}^{+}{ }^{+} \mathrm{T}$ cell survival. Purified PBMC cells naturally undergo apoptosis in 
A
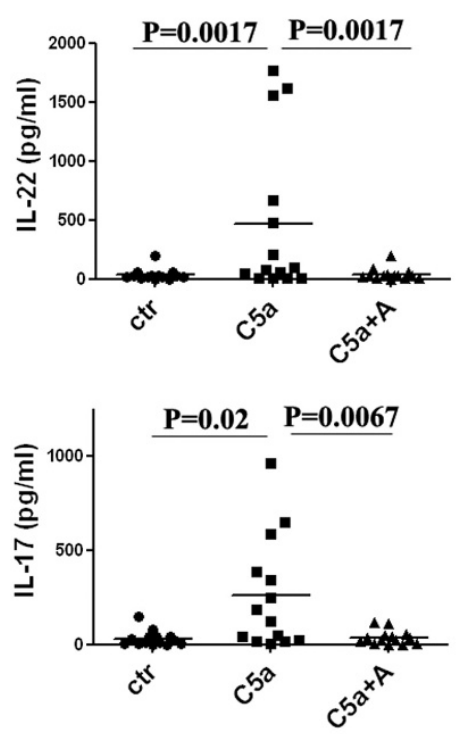

B

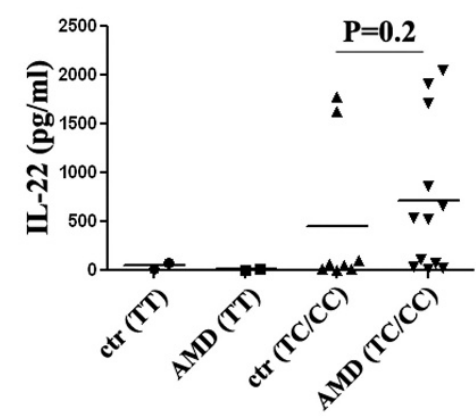

C

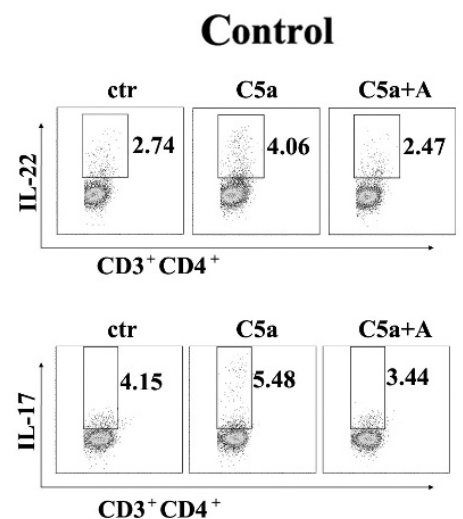

\section{Control}
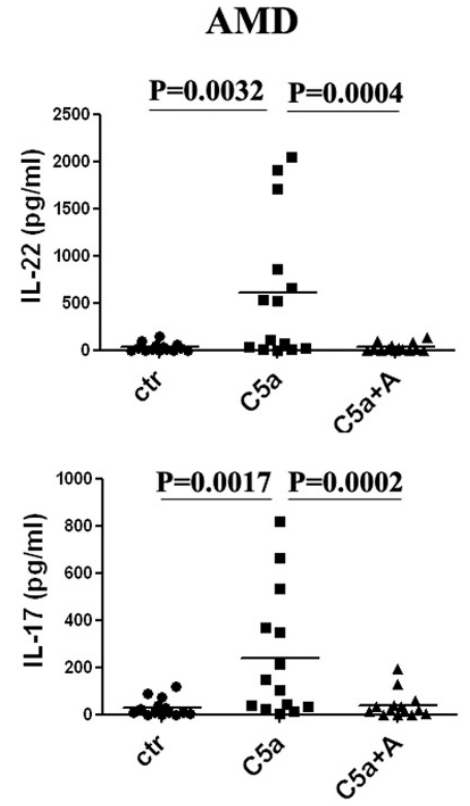

AMD

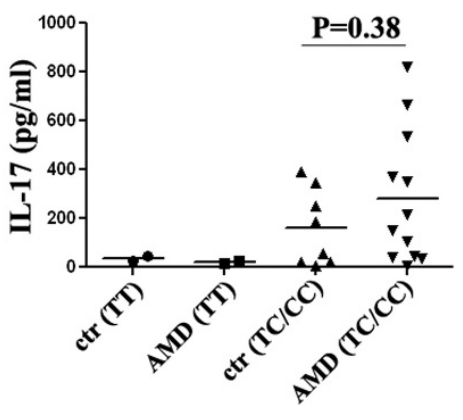

AMD
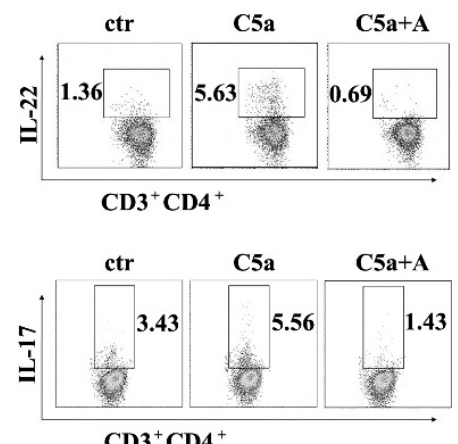

$\mathrm{CD}^{+} \mathrm{CD}^{+}$

Figure 1 C5a promotes the expression of IL-22 and IL-17 from T cells. (A) IL-22 and IL-17 in 3-day culture supernatants of PBMCs from 14 AMD patients and 14 controls. (B) C5a induced IL-22/IL-17 expression in both controls and AMD patients were subgrouped based on CFH genotypes. (C) Intracytoplasmic staining of IL-22 and IL-17 from both controls and AMD patients after 5 days of culture with or without C5a and C5aR antagonist. 


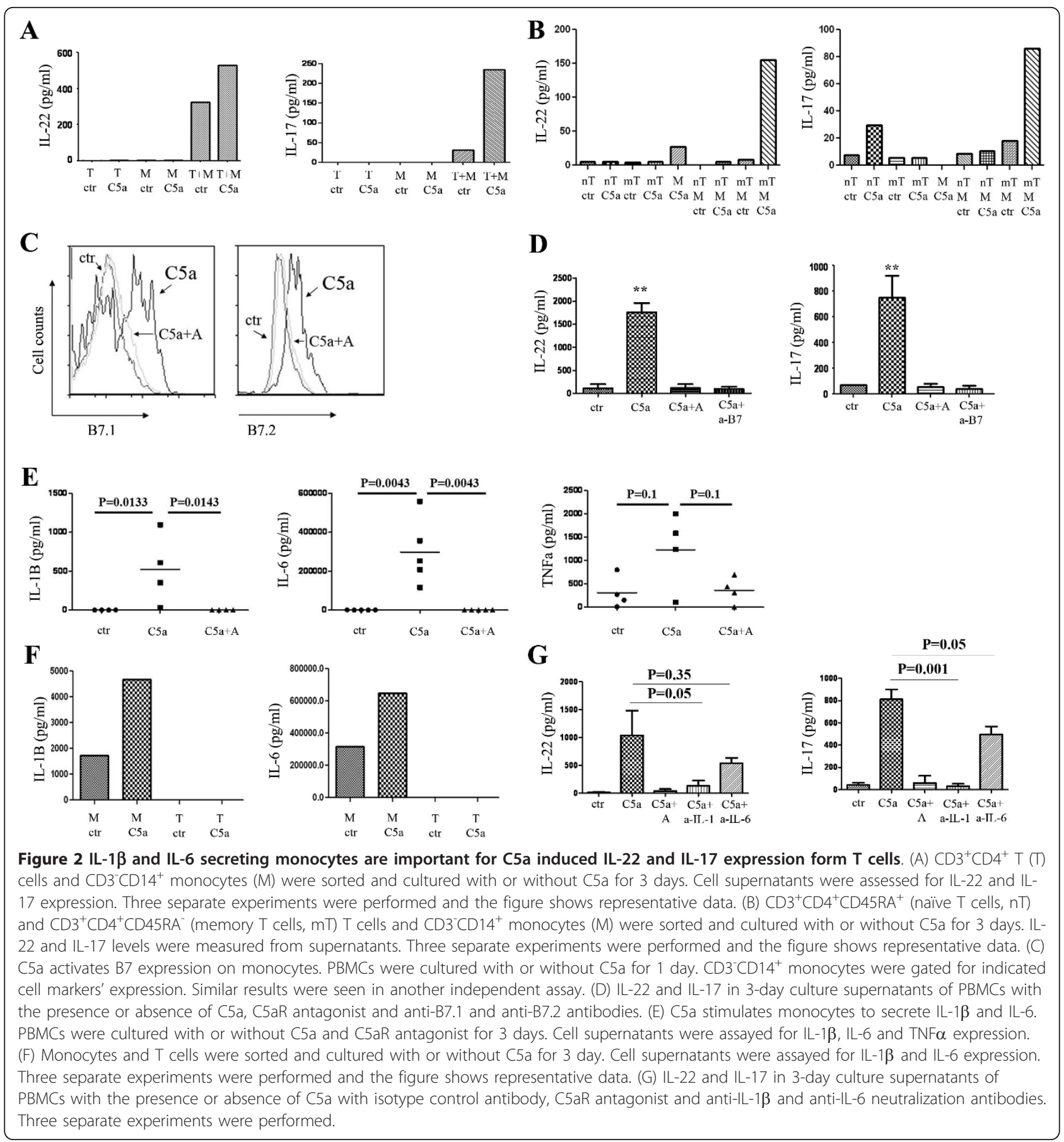

culture and they usually die without stimulation in 7 days. We added C5a with or without the C5aR antagonist to the culture for 2 days and compared the percentage of cells undergoing apoptosis for more than 10 individuals. Morphological signs of the inhibition of apoptosis, including more cell aggregates and less shrunken cells, were observed in C5a group. Figure 3A represents a typical flow cytometry scatter plot. The percentages of lymphocyte and monocyte gates increased after C5a treatment (from $41 \%$ to $52.8 \%$ and $5.96 \%$ to $17.0 \%$ respectively). Further apoptosis staining showed that the addition of $\mathrm{C} 5 \mathrm{a}$ prevented $\mathrm{CD} 4^{+} \mathrm{T}$ cells from undergoing apoptosis, as indicated by annexin $\mathrm{V}$ staining. This effect was abrogated by the addition of a C5aR antagonist (Figure 3B). TUNEL staining confirmed these results. Apoptotic cells were labeled with fluorescein. Fluorescein labeled cells had less intense staining in C5a treatment group as compared to the control group (Figure $3 \mathrm{C}$ ). 


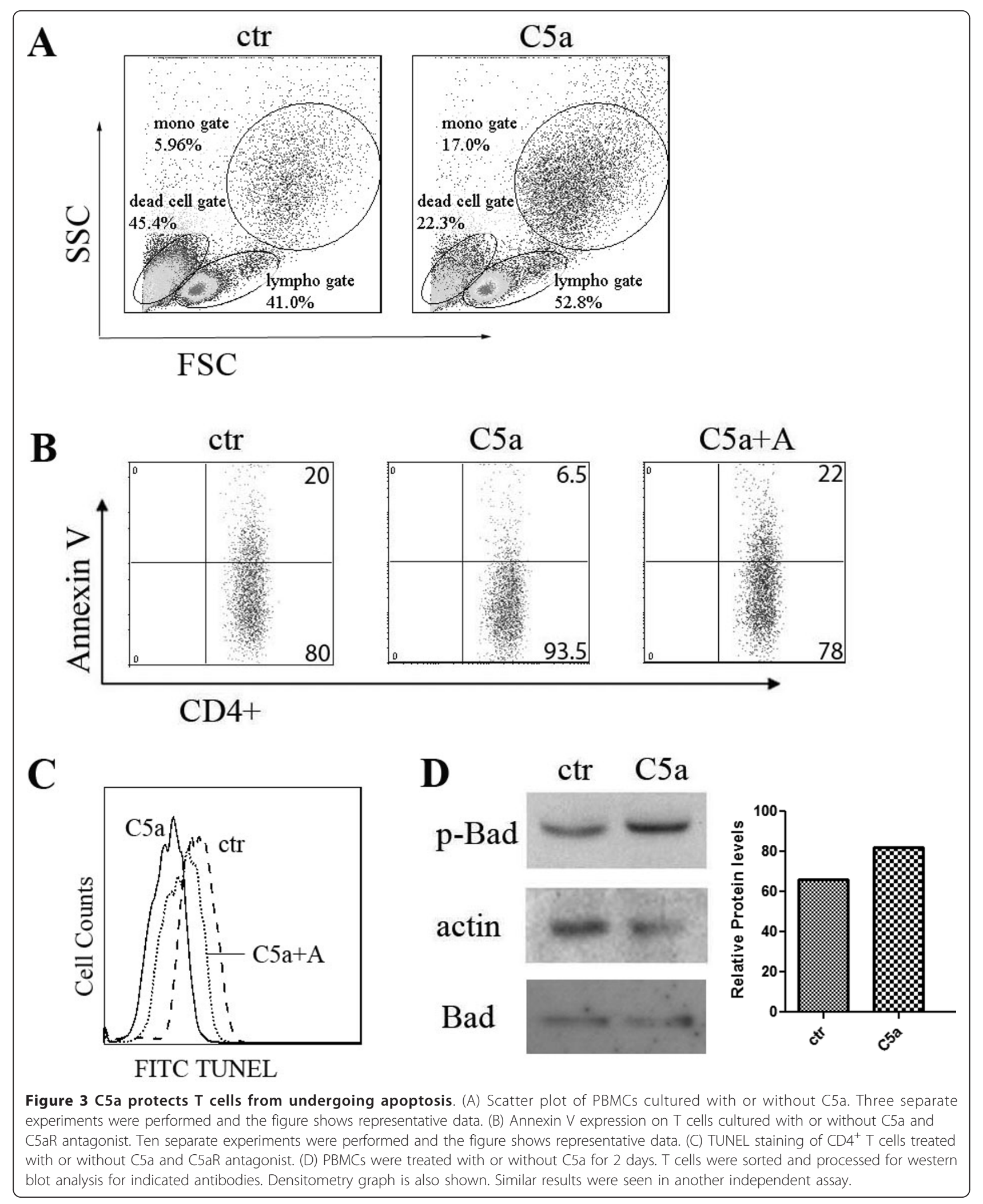


Moreover, the expression of Phospho-Bad, one of the anti-apoptotic indicators, was increased in $\mathrm{CD} 4^{+} \mathrm{T}$ cells after C5a treatment (Figure 3D).

Higher IL-22 and IL-17 expression in AMD patients Different cohort studies have shown elevated levels of C5a in AMD blood as compared to controls $[15,16]$. Based on our in vitro data that C5a induced Th17 cytokine expression from human $\mathrm{T}$ cells, we want to do a pilot study to evaluate the expression of IL-22 and IL-17 in the serum of AMD patients. As shown in Figure 4, IL-22 and IL-17 levels were significantly elevated in AMD patients compared with controls. We then subgrouped cytokine expression in both the controls and the AMD patients based on their CFH SNP information (rs1061170). As shown in Figure 4, IL-22/IL-17 cytokine high expression AMD patients have the risk $\mathrm{CFH}$ allele genotypes (heterozygous/homozygous, TC/CC). However, for control group, IL-22/IL-17 expressions remained low regardless of their CFH SNP genotypes. We performed the association study between IL-22/IL17 cytokine expressions and some characteristics of patients (CFH, C2/CFB, C3 genotypes, age, gender, comorbidities of diabetes, hypertension and hypercholesterolemia). Our results indicated that there were no statistically significant associations between IL-22/IL-17 cytokine expressions and these variances (all $\mathrm{P}$ values are more than 0.05 , Additional file 1: Table S1).

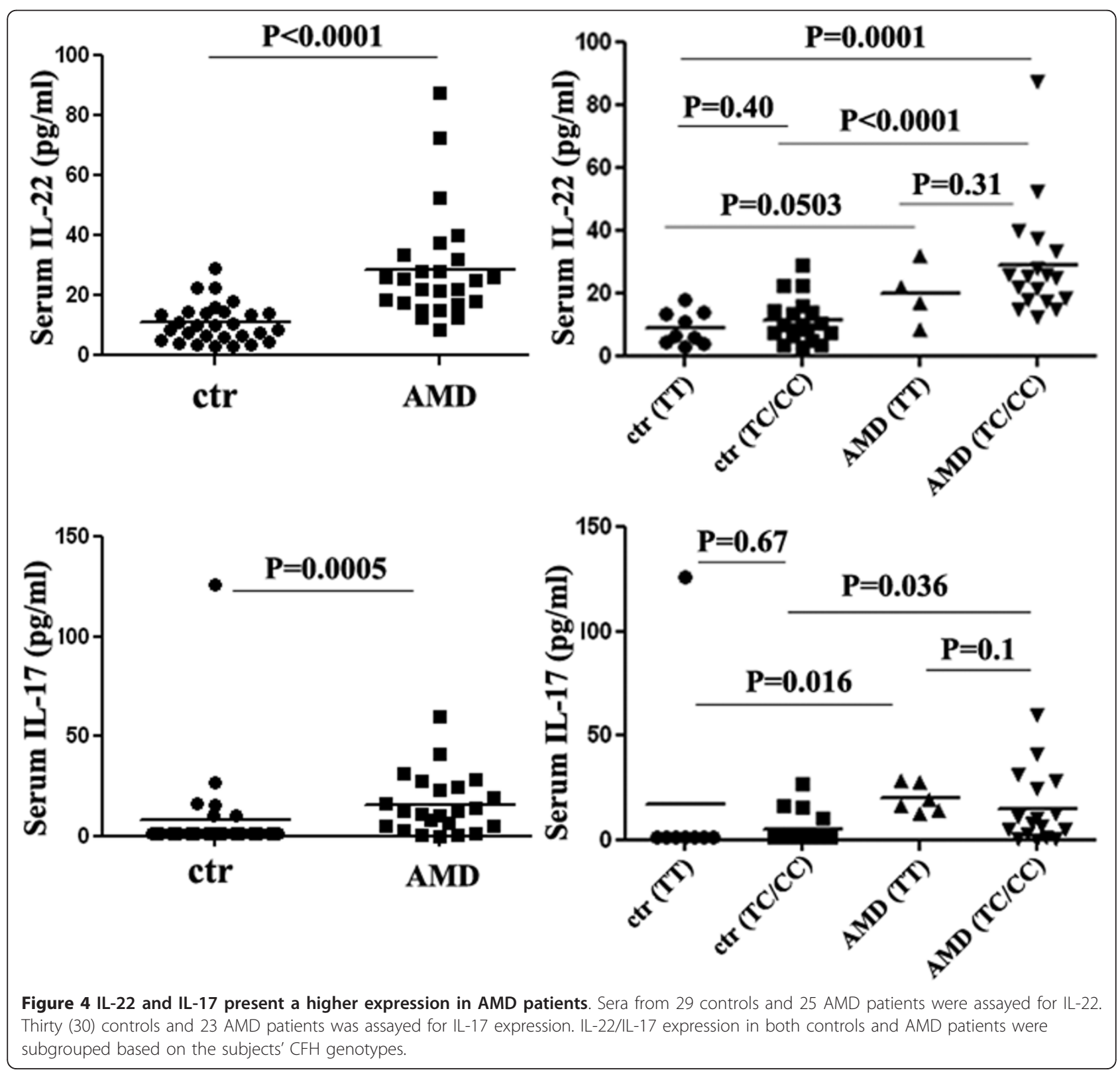




\section{Discussion}

In this study, we have provided evidence that $\mathrm{C} 5 \mathrm{a}$ induced IL-22 and IL-17A expression from human CD4 ${ }^{+}$ $\mathrm{T}$ cells. Importantly, consistent with previous observations of elevated C5a expression in the serum of AMD patients from different cohorts $[15,16]$, we observed significantly increased levels of IL-22 and IL-17A in the sera of AMD patients. However, so far, we do not have direct evidence showing that the elevated Th17 cytokine levels in AMD patients' sera are due to higher C5a expression in AMD patients. C5a may be one of the many factors related to this observed effect. Other unknown factors may also contribute to this T cell activation seen in AMD patients. Interestingly, the findings that $\mathrm{C} 5$ a specifically promoted the Th17 family cytokine production, but not IFN $\kappa$ nor IL-4, also correlated with the fact that there were similar IFN $\kappa$ and IL-4 levels in the sera of AMD patients as compared to controls. The dysregulation of the complement system has been linked to multiple neurodegenerative diseases including Alzheimer's disease, Parkinson's disease, as well as AMD [29]. The induction of inflammatory Th17 cytokines, including IL-22 and IL17 , by complement component C5a could potentially elucidate the general mechanism by which inflammation contributes to the pathogenesis of these diseases previously referred to as degenerative. Our results support a role for $\mathrm{C} 5 \mathrm{a}$ in protecting $\mathrm{CD} 4^{+} \mathrm{T}$ cells from undergoing apoptosis (Figure 3 ). These findings suggest that the enhanced effector $\mathrm{T}$ cell function by $\mathrm{C} 5 \mathrm{a}$ is at least partially mediated by limiting pro-inflammatory cell death.

We found that monoctytes are necessary for C5a induced Th17 cytokine production through two mechanisms: 1$)$ promoting the direct interaction between monocytes and T cells; 2 ) indirectly stimulating the production of IL- $1 \beta$ and IL- 6 from monocytes. C5a can bind to the trans-membrane receptors $\mathrm{C} 5 \mathrm{aR} / \mathrm{CD} 88$ and $\mathrm{C} 5 \mathrm{~L} 2$ (GPR77) which are expressed on monocytes. C5L2 is expressed at much lower levels as compared to CD88. C5a binding to CD88 leads to a number of functional changes including activation of inflammation. However, the pathophysiological role of C5L2 is currently controversial with both pro-inflammatory and anti-inflammatory roles reported [30]. Previous reports from rodent models have shown that $\mathrm{C} 5 \mathrm{a}$ has a direct effect on $\mathrm{T}$ cells by interacting with the $\mathrm{C} 5 \mathrm{a}$ receptor expressed on $\mathrm{T}$ cells, a finding which is different from what we have observed in humans [26]. Fang et al. recently demonstrated that C5a itself has no effect on Th17 cytokine production in mouse [31]. However, C5a synergizes with TLR4 to produce serum factors that drive Th17 cell differentiation [31]. Liu et al. reported that local interactions among $\mathrm{C} 3 \mathrm{a} / \mathrm{C} 5 \mathrm{a}, \mathrm{C} 3 \mathrm{aR} / \mathrm{C} 5 \mathrm{aR}$, antigen presenting cells (APC) and T cells are important for IFN $\kappa$ and IL-17 production of $\mathrm{T}$ cells in a murine EAE (Experimental autoimmune encephalomyelitis) model [32]. In another murine sepsis model, $\mathrm{Xu}$ et al. shows that C5a affects the crosstalk between DC and gamma/delta $\mathrm{T}$ cells and results in a large production of IL-17[33]. In a human study, Hueber and colleagues showed that C5a induces IL-17 from human mast cells [34]. Our work is the first human study showing that monocytes play an essential role in C5a promoted expression of Th17 cytokines from $\mathrm{CD} 4^{+} \mathrm{T}$ cells.

Several research teams have reported that a common SNP of $\mathrm{CFH}$, $\mathrm{Tyr}^{402} \mathrm{His}$, has a particularly strong association with AMD $[4,6,8]$. We sub-grouped IL-22/IL-17 expression based on the subjects' CFH SNP genotypes and found that AMD patients with higher IL-22/IL-17 cytokine expression were likely to have the risk CFH allele (TC/CC) (Figure 4). However, serum IL-22/IL-17 cytokine levels showed no difference between the two $\mathrm{CFH}$ genotype groups (TT versus $\mathrm{TC} / \mathrm{CC}$ ) in controls. These results suggest that this CFH SNP does not explain the elevated Th17 cytokine expression. However, this genetic variant may be one of the many factors influencing Th17 cytokine expression.

Dysregulation of alternative complement activation has been reported to be involved in AMD pathogenesis. The drusen of AMD donor eyes contain almost all molecules of the alternative complement pathway, including $\mathrm{CFH}$, C3, C5, C3a, C5a, and the membrane attack complex (MAC) [35-37]. These results suggest the role of the complement system in the eye. The products of complement activation can also be detected in the blood of AMD patients. Scholl et al. [16] found higher levels of alternative complement activation molecules in the blood from an AMD cohort, including Ba, C3d, MAC, C3a, and C5a. A subsequent study in a larger independent cohort of patients and controls confirmed these results, showing the activation of the alternative pathway of complement in blood is associated with genetic polymorphisms in complement factor B and increases with age [14]. Reynolds and colleagues also found an increased plasma concentration of $\mathrm{C} 5 \mathrm{a}$ and $\mathrm{Bb}$ in advanced AMD [15]. In addition, a recent report has shown that immunization with carboxyethylpyrrole generated by oxidative damage to DHA (Docosahexaenoic acid) present in the drusen and plasma from AMD-affected individuals is sufficient to produce AMD like lesions in mice and antibody titers of carboxyethylpyrrole correlates with disease pathology, suggesting the involvement of the acquired immune pathway in disease pathology [38]. In this study, we found C5a induced Th17 cytokine expression from human $\mathrm{T}$ cells in vitro, which correlates with the increased levels of Th17 cytokines in AMD blood. IL-22 has been shown to induce apoptosis of fetal retinal pigment epithelium (RPE) cells 
and reduce RPE cell electrical resistance in culture [39]. However, whether systemic observations reflects pathological events in the eye and how systemic activation may ultimately be manifest in the eye remain to be defined.

To date there is no effective treatments other than attempts to slow the progression of geographic atrophy form of AMD, while neovascular AMD is treated with anti-VEGF medications injected directly into the eye $[40,41]$. Previous attempts at controlling the wet form of AMD with corticosteroid therapy have shown that the beneficial effect is transient with a significant side-effect risk profile [42]. Health improving behavior (no-smoking), diet, and exercise may be preventive measures for AMD [43]. Several compounds targeting complement pathway are currently in clinical trials [13]. We recently reported that immunotherapy directed against $\mathrm{T}$-cell activation resulted in patients with recurrent $\mathrm{CNV}$ requiring fewer injections of anti-VEGF [44]. The dysregulation of the acquired immune pathway we describe here may provide us with new therapeutic strategies.

\section{Conclusion}

In conclusion, we have shown that $\mathrm{C} 5 \mathrm{a}$ promoted expression of Th17 cytokines from human $\mathrm{CD} 4^{+} \mathrm{T}$ cells. Consistent with several cohort observation of elevated C5a expression in the serum of AMD patients [14-16], our results support the notion that C5a may be one of the factors contributing to the elevated serum IL-22 and IL-17 levels in AMD patients. Targeting adaptive immune system, more specifically the Th17 family of cytokines, may have beneficial effect on the course of AMD.

\section{Additional material}

Additional file 1: Table S1 Association between the serum levels of IL-22/IL-17 with patients' characteristics. P values were listed for the association between IL-22/L-17 and some characteristics of patients (CFH, C2/CFB, C3 genotypes, gender, co-morbidities of diabetes, hypertension and hypercholesterolemia). Age was analyzed using Pearson correlation.

\section{Abbreviations \\ AMD: Age related macular degeneration; $\mathrm{CFH}$ : complement factor $\mathrm{H}$; IL: interleukin; RPE: retinal pigment epithelium; PBMC: peripheral blood mononuclear cell; SNP: single nucleotide polymorphism}

\section{Acknowledgements}

We thank Dr. Anthony Adamis for kindly providing the C5aR antagonist; Rafael Villasmil for assistance with flow cytometric cell sorting; This research was supported by the Intramural Research Program of NIH, National Eye Institute.

\section{Author details}

'Laboratory of Immunology, National Eye Institute, National Institutes of Health, Bethesda, MD 20892, USA. ${ }^{2}$ Division of Epidemiology and Clinical Research, National Eye Institute, National Institutes of Health, Bethesda, MD
20892, USA. ${ }^{3}$ Macular Degeneration Center and Leonard Christensen Eye Pathology Laboratory, Casey Eye Institute, Oregon Health \& Science University, Portland, OR 97239, USA.

\section{Authors' contributions}

$\mathrm{BL}, \mathrm{RBN}$ have conceived and designed the research and drafted the manuscript; $B L, L W, J T, Z L, S C$ have performed the experiments. CM, HNS, CCC, MLK, EC, FF have provided materials and clinical samples and help analyzed the clinical data. EA, BL performed statistical analysis. All authors read and approved the final manuscript.

\section{Competing interests}

The authors declare that they have no competing interests.

Received: 13 May 2011 Accepted: 15 July 2011 Published: 15 July 2011

\section{References}

1. Ferris FL, Fine SL, Hyman L: Age-related macular degeneration and blindness due to neovascular maculopathy. Arch Ophthalmol 1984, 102:1640-1642.

2. Nussenblatt RB, Liu B, Li Z: Age-related macular degeneration: an immunologically driven disease. Curr Opin Investig Drugs 2009, 10:434-442.

3. Patel M, Chan CC: Immunopathological aspects of age-related macular degeneration. Semin Immunopathol 2008, 30:97-110.

4. Edwards AO, Ritter R, Abel KJ, Manning A, Panhuysen C, et al: Complement factor $\mathrm{H}$ polymorphism and age-related macular degeneration. Science 2005, 308:421-424.

5. Gold B, Merriam JE, Zernant J, Hancox LS, Taiber AJ, et al: Variation in factor $\mathrm{B}(\mathrm{BF})$ and complement component 2 (C2) genes is associated with age-related macular degeneration. Nat Genet 2006, 38:458-462.

6. Hageman GS, Anderson DH, Johnson LV, Hancox LS, Taiber AJ, et al: A common haplotype in the complement regulatory gene factor $\mathrm{H}$ (HF1/ CFH) predisposes individuals to age-related macular degeneration. Proc Natl Acad Sci USA 2005, 102:7227-7232.

7. Jakobsdottir J, Conley YP, Weeks DE, Ferrell RE, Gorin MB: C2 and CFB genes in age-related maculopathy and joint action with $\mathrm{CFH}$ and LOC387715 genes. PLoS One 2008, 3:e2199.

8. Klein RJ, Zeiss C, Chew EY, Tsai JY, Sackler RS, et al: Complement factor H polymorphism in age-related macular degeneration. Science 2005, 308:385-389.

9. Maller JB, Fagerness JA, Reynolds RC, Neale BM, Daly MJ, et al: Variation in complement factor 3 is associated with risk of age-related macular degeneration. Nat Genet 2007, 39:1200-1201.

10. Spencer KL, Hauser MA, Olson LM, Schmidt S, Scott WK, et al: Protective effect of complement factor B and complement component 2 variants in age-related macular degeneration. Hum Mol Genet 2007, 16:1986-1992.

11. Spencer KL, Olson LM, Anderson BM, Schnetz-Boutaud N, Scott WK, et al: C3 R102G polymorphism increases risk of age-related macular degeneration. Hum Mol Genet 2008, 17:1821-1824.

12. Yates JR, Sepp T, Matharu BK, Khan JC, Thurlby DA, et al: Complement C3 variant and the risk of age-related macular degeneration. $N$ Engl J Med 2007, 357:553-561.

13. Charbel Issa P, Chong NV, Scholl HP: The significance of the complement system for the pathogenesis of age-related macular degeneration current evidence and translation into clinical application. Graefes Arch Clin Exp Ophthalmol 2011, 249:163-174.

14. Hecker LA, Edwards AO, Ryu E, Tosakulwong N, Baratz KH, et al: Genetic control of the alternative pathway of complement in humans and agerelated macular degeneration. Hum Mol Genet 2010, 19:209-215.

15. Reynolds R, Hartnett ME, Atkinson JP, Giclas PC, Rosner B, et al: Plasma complement components and activation fragments: associations with age-related macular degeneration genotypes and phenotypes. Invest Ophthalmol Vis Sci 2009, 50:5818-5827.

16. Scholl HP, Charbel Issa P, Walier M, Janzer S, Pollok-Kopp B, et al: Systemic complement activation in age-related macular degeneration. PLOS One 2008, 3:e2593.

17. Nozaki M, Raisler BJ, Sakurai E, Sarma JV, Barnum SR, et al: Drusen complement components C3a and C5a promote choroidal neovascularization. Proc Natl Acad Sci USA 2006, 103:2328-2333.

18. Caspi R: Autoimmunity in the immune privileged eye: pathogenic and regulatory T cells. Immunol Res 2008, 42:41-50. 
19. Weaver CT, Hatton RD, Mangan PR, Harrington LE: IL-17 family cytokines and the expanding diversity of effector T cell lineages. Annu Rev Immunol 2007, 25:821-852.

20. Zheng Y, Danilenko DM, Valdez P, Kasman I, Eastham-Anderson J, et al: Interleukin-22, a $\mathrm{T}(\mathrm{H}) 17$ cytokine, mediates IL-23-induced dermal inflammation and acanthosis. Nature 2007, 445:648-651.

21. Manel N, Unutmaz D, Littman DR: The differentiation of human $\mathrm{T}(\mathrm{H})-17$ cells requires transforming growth factor-beta and induction of the nuclear receptor RORgammat. Nat Immunol 2008, 9:641-649.

22. Volpe E, Servant N, Zollinger R, Bogiatzi SI, Hupe P, et al: A critical function for transforming growth factor-beta, interleukin 23 and proinflammatory cytokines in driving and modulating human $\mathrm{T}(\mathrm{H})-17$ responses. Nat Immunol 2008, 9:650-657.

23. Wilson NJ, Boniface K, Chan JR, McKenzie BS, Blumenschein WM, et al: Development, cytokine profile and function of human interleukin 17producing helper T cells. Nat Immunol 2007, 8:950-957.

24. Yang L, Anderson DE, Baecher-Allan C, Hastings WD, Bettelli E, et al: IL-21 and TGF-beta are required for differentiation of human $\mathrm{T}(\mathrm{H}) 17$ cells. Nature 2008, 454:350-352.

25. Lalli PN, Strainic MG, Yang M, Lin F, Medof ME, et al: Locally produced C5a binds to $\mathrm{T}$ cell-expressed $\mathrm{C} 5 \mathrm{aR}$ to enhance effector T-cell expansion by limiting antigen-induced apoptosis. Blood 2008, 112:1759-1766.

26. Strainic MG, Liu J, Huang D, An F, Lalli PN, et al: Locally produced complement fragments $\mathrm{C} 5 \mathrm{a}$ and $\mathrm{C} 3 \mathrm{a}$ provide both costimulatory and survival signals to naive CD4+ T cells. Immunity 2008, 28:425-435.

27. Acosta-Rodriguez EV, Napolitani G, Lanzavecchia A, Sallusto F: Interleukins 1 beta and 6 but not transforming growth factor-beta are essential for the differentiation of interleukin 17-producing human T helper cells. Nat Immunol 2007, 8:942-949.

28. Bradshaw EM, Raddassi K, Elyaman W, Orban T, Gottlieb PA, et al: Monocytes from patients with type 1 diabetes spontaneously secrete proinflammatory cytokines inducing Th17 cells. J Immunol 2009, 183:4432-4439.

29. Yanamadala V, Friedlander RM: Complement in neuroprotection and neurodegeneration. Trends Mol Med 2010, 16:69-76.

30. Woodruff TM, Nandakumar KS, Tedesco F: Inhibiting the C5-C5a receptor axis. Mol Immunol 2011.

31. Fang C, Zhang X, Miwa T, Song WC: Complement promotes the development of inflammatory T-helper 17 cells through synergistic interaction with Toll-like receptor signaling and interleukin-6 production. Blood 2009, 114:1005-1015.

32. Liu J, Lin F, Strainic MG, An F, Miller RH, et al: IFN-gamma and IL-17 production in experimental autoimmune encephalomyelitis depends on local APC-T cell complement production. J Immunol 2008, 180:5882-5889.

33. Xu R, Wang R, Han G, Wang J, Chen G, et al: Complement C5a regulates IL-17 by affecting the crosstalk between $\mathrm{DC}$ and gammadelta T cells in CLP-induced sepsis. Eur J Immunol 2010, 40:1079-1088.

34. Hueber AJ, Asquith DL, Miller AM, Reilly J, Kerr S, et al: Mast cells express IL-17A in rheumatoid arthritis synovium. J Immunol 2010, 184:3336-3340.

35. Anderson DH, Radeke MJ, Gallo NB, Chapin EA, Johnson PT, et al: The pivotal role of the complement system in aging and age-related macular degeneration: hypothesis re-visited. Prog Retin Eye Res 2010, 29:95-112.

36. Crabb JW, Miyagi M, Gu X, Shadrach K, West KA, et al: Drusen proteome analysis: an approach to the etiology of age-related macular degeneration. Proc Natl Acad Sci USA 2002, 99:14682-14687.

37. Johnson LV, Leitner WP, Staples MK, Anderson DH: Complement activation and inflammatory processes in Drusen formation and age related macular degeneration. Exp Eye Res 2001, 73:887-896.

38. Hollyfield JG, Bonilha VL, Rayborn ME, Yang X, Shadrach KG, et al: Oxidative damage-induced inflammation initiates age-related macular degeneration. Nat Med 2008, 14:194-198.

39. Li Z, Liu B, Maminishkis A, Mahesh SP, Yeh S, et al: Gene expression profiling in autoimmune noninfectious uveitis disease. J Immunol 2008, 181:5147-5157.

40. Hubschman JP, Reddy S, Schwartz SD: Age-related macular degeneration: current treatments. Clin Ophthalmol 2009, 3:155-166.

41. Ranibizumab and Bevacizumab for Neovascular Age-Related Macular Degeneration. N Engl J Med 2011.

42. Kiernan DF, Mieler WF: The use of intraocular corticosteroids. Expert Opin Pharmacother 2009, 10:2511-2525.
43. Wong IY, Koo SC, Chan CW: Prevention of age-related macular degeneration. Int Ophthalmol 2011, 31:73-82.

44. Nussenblatt RB, Byrnes $G$, Sen N, Yeh S, Faia L, et al: A randomized pilot study of systemic immunosuppression in the treatment of age-related macular degeneration with choroidal neovascularization. Retina 2010, 30:1579-1587.

doi:10.1186/1479-5876-9-111

Cite this article as: Liu et al:: Complement component C5a Promotes Expression of IL-22 and IL-17 from Human T cells and its Implication in Age-related Macular Degeneration. Journal of Translational Medicine 2011 9:111.

\section{Submit your next manuscript to BioMed Central and take full advantage of:}

- Convenient online submission

- Thorough peer review

- No space constraints or color figure charges

- Immediate publication on acceptance

- Inclusion in PubMed, CAS, Scopus and Google Scholar

- Research which is freely available for redistribution 